\title{
Research on Pavement Roughness Based on the Laser Triangulation
}

\author{
Wenxue CHEN ${ }^{*}$, Zhibin NI, Xinhan HU, and Xiaofeng LU \\ Equipment Academy of the Rocket Force, Beijing, 100094, China \\ *Corresponding author: Wenxue CHEN_E-mail: 200231030072@whu.edu.cn
}

\begin{abstract}
Pavement roughness is one of the most important factors for appraising highway construction. In this paper, we choose the laser triangulation to measure pavement roughness. The principle and configuration of laser triangulation are introduced. Based on this technology, the pavement roughness of a road surface is measured. The measurement results are given in this paper. The measurement range of this system is $50 \mu \mathrm{m}$. The measurement error of this technology is analyzed. This technology has an important significance to appraise the quality of highway after completion of the workload.
\end{abstract}

Keywords: Pavement roughness; laser triangulation; measurement

Citation: Wenxue CHEN, Zhibin NI, Xinhan HU, and Xiaofeng LU, "Research on Pavement Roughness Based on the Laser Triangulation," Photonic Sensors, 2016, 6(2): 177-180.

\section{Introduction}

In recent years, with the development of highway construction, the testing and maintenance on highway construction after completion has became an important work. Thus, the requirements to the road detection level become higher. Among many indicators which affect the car comfort and safety, the pavement roughness is an important factor which represents the quality of highway driving. According to the full knowledge of the international standard $[1,2]$, the pavement roughness is chosen to appraise the quality of highway in this paper.

The laser triangulation has been widely used in industrial field with the characteristics of high speed, small size, automation, large scale, non-contact measurement, and high precision [3-10]. In this paper, the laser triangulation is chosen to measure the pavement roughness.

In this paper, the principle and configuration of the laser triangulation are introduced. The pavement roughness is measured based on the laser triangulation. The measurement error of the laser triangulation is analyzed.

\section{Setup}

The detecting system of pavement roughness is shown in Fig. 1. The laser triangulation is installed on the chassis to reduce the influence induced by the jounce. The laser triangulation emits the laser to measure the distance between the jounce and road surface. The variation of measuring distance represents the pavement roughness. In order to reduce the jounce, the car runs at a low speed.

The configuration of the laser triangulation is shown in Fig. 2. Here, we use the laser diode (LD) as the light source. Firstly, the LD emits the laser. The

Received: 12 September 2015 / Revised: 2 March 2016

(C) The Author(s) 2016. This article is published with open access at Springerlink.com

DOI: $10.1007 / \mathrm{s} 13320-016-0288-\mathrm{x}$

Article type: Regular 
transmitted light passes through the diaphragm. After that, the laser beam reaches the measured object. One part of the laser, which is called the scattered light, is reflected to go through the light filter. The scattered light contains the displacement information of the measured object. It goes through the lens and reaches the complementary metal oxide semiconductor (CMOS). When the position of the measured object varies, the position of the scattered light on the CMOS will change. Thus, the displacement of the measured object can be detected by measuring the position of the scattered light. This is the measurement principle of the laser triangulation.

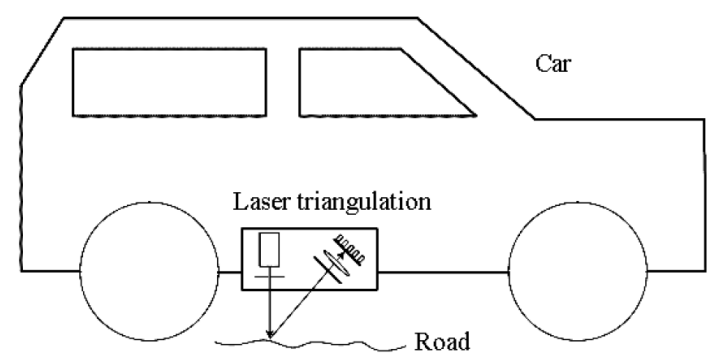

Fig. 1 Measurement setup of pavement roughness.

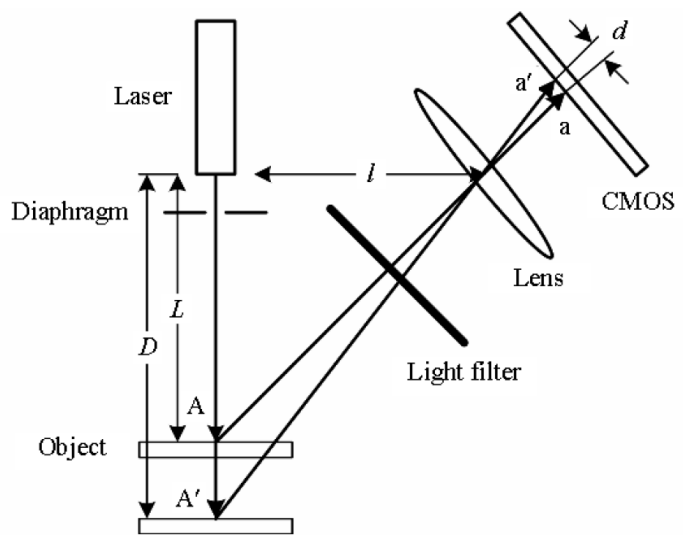

Fig. 2 Configuration of the laser triangulation.

The configuration of the laser triangulation can be divided into four parts: a light source, a filter, a signal detecting, and a signal acquisition system.

A laser diode with the wavelength of $655 \mathrm{~nm}$ is used as the light source. The intensity of laser is $0.56 \mathrm{~mW}$. The radiation angle and diameter of the laser are $0.4 \mathrm{mrad}$ and $1.6 \mathrm{~mm}$, respectively. The working voltage of the LD is $3.3 \mathrm{~V}$. The electric current is $35 \mathrm{~mA}$. The working temperature of the LD is $0{ }^{\circ} \mathrm{C}$. The LD which is chosen as the optical source in our system has the advantages of small size, tiny weight, and small radiation angle. That ensures the narrow ray width of LD laser to improve the measurement precision.

The filter is made up of the diaphragm and optical filter. The diaphragm is used to reduce the diameter of ray. The central wavelength of the optical filter is $655 \mathrm{~nm}$, and the transmittance ratio of the optical filter is larger than $90 \%$ at the wavelength of $655 \mathrm{~nm}$. The transmittance ratio is almost zero at the other wavelength.

The signal detecting part is formed by the lens and CMOS.

A signal acquisition system is used to acquire the output of CMOS and deal with the data. The acquire rate of the signal is $3 \mathrm{kHz}$. The output voltage of the system is between 0 and $5 \mathrm{~V}$. The relationship between the displacement of the measured object and the output voltage of the system is linear. Thus, the output voltage $V$ represents the displacement $D$ of the measured object. The formula is given as (1):

$$
D=0.16 V+0.2 \text {. }
$$

Based on the relationship between the object and image, the distance between the measured object and the LD laser is expressed as

$$
D=\frac{d \times\left(f \times \sqrt{L^{2}+l^{2}}-l^{2}\right)-f \times l \times L}{d \times L-f \times l} .
$$

The sign meanings in (2) are shown in Fig. 2.

\section{Results}

We measure the pavement roughness based on the laser triangulation, and the result obtained is displayed in Fig. 3. In the measurement, 2000 seconds data are acquired to evaluate the road quality. In order to reduce the error induced by the jounce, the car runs at a speed about $30 \mathrm{~km} / \mathrm{h}$. 
As shown in Fig. 3, the maximum value of the roughness is $18 \mathrm{~mm}$.

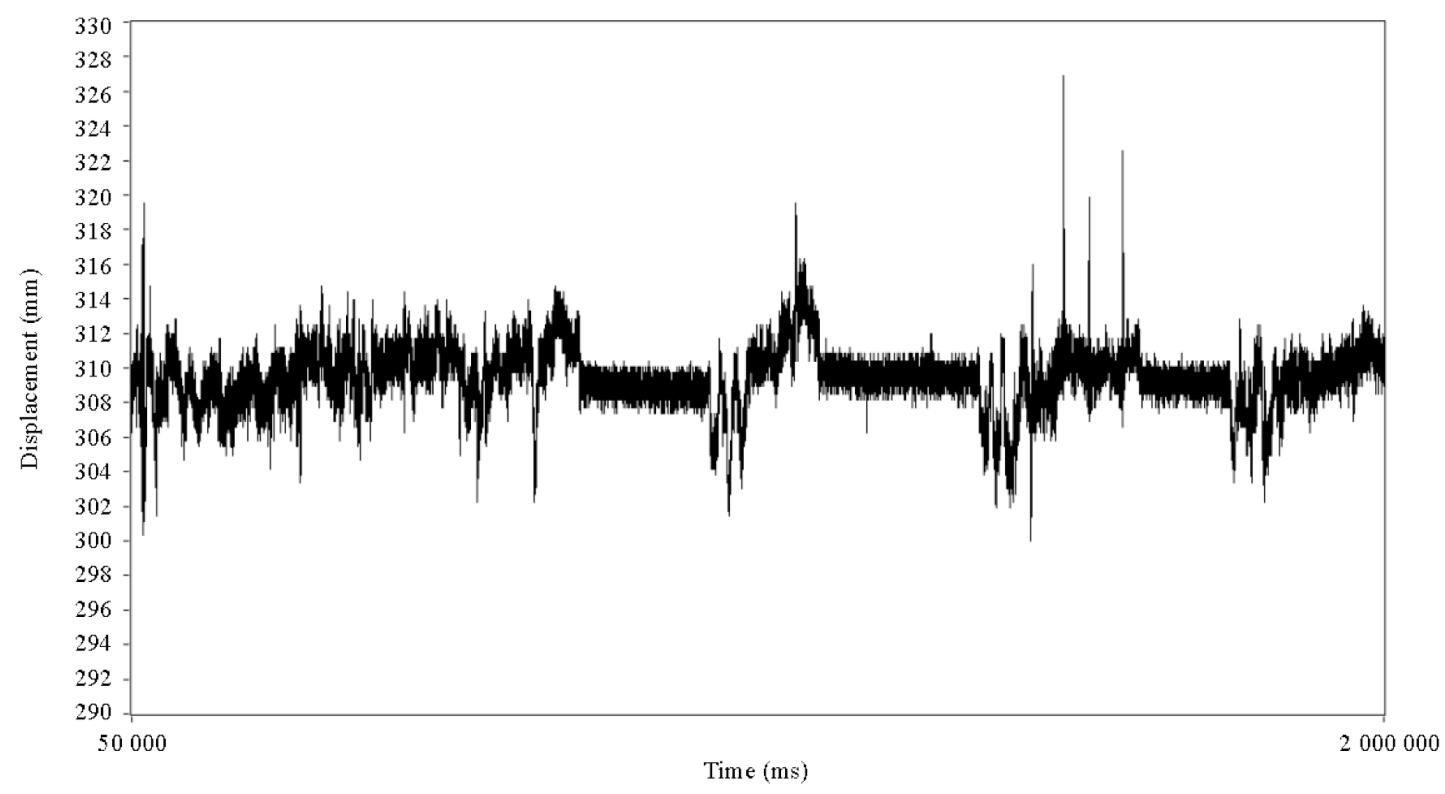

Fig. 3 Measurement result of the pavement roughness.

\section{Error analysis}

The error is mainly induced by the instability of the light source, installation error, and so on.

The wavelength of LD laser is influenced by the temperature. The variation of the wavelength will change the ray diameter. This will introduce the error during the image processing.

The installation processing will introduce the error into the measurement system. For example, the Scheimpflug condition of the position relationship among the CMOS, the ray axis of lens, and laser ray is not satisfied.

\section{Summary}

In this paper, the laser triangulation is applied to measure the pavement roughness. The principle and configuration of the laser triangulation are introduced. The pavement roughness is measured, and the maximum roughness is $18 \mathrm{~mm}$. The measurement error is analyzed. The work in this paper has a contribution to the measurement of pavement roughness.

\section{Acknowledgment}

This work is supported by the National Natural Science Foundation of China (NSFC) (Grant No. 61505255).

Open Access This article is distributed under the terms of the Creative Commons Attribution 4.0 International License (http://creativecommons.org/ licenses/by/4.0/), which permits unrestricted use, distribution, and reproduction in any medium, provided you give appropriate credit to the original author(s) and the source, provide a link to the Creative Commons license, and indicate if changes were made.

\section{Reference}

[1] L. Shen, D. Li, and F. Luo, "Study on laser speckle correlation method applied in triangulation displacement measurement," Journal of Optical Technology, 2013, 80(10): 604-610.

[2] D. Wu, Q. Lu, X. Chen, and B. Ge, "Analysis on measurement range and precision of the oil film thickness measurement sensor based on differential laser trigonometry," Journal of Tianjin University (Science and Technology), 2013, 46(11): 999-1002.

[3] T. Cui, X. Shen, J. Hu, D. Li, and J. Li, "Tightness testing of gas meter valve based on laser 
triangulation," Opto-Electronic Engineering, 2013, 40(7): 71-76.

[4] J. Chu, D. Li, F. Luo, and M. Liu, "Fuzzy adaptive control of light in laser triangulation displacement measurement," Medicina Clínica, 2013, 124(3): 106-107.

[5] M. Sayers, T. Gillespie, and C. Queiroz, The international road roughness experiment: establishing correlation and calibration standard for measurements. Washington: World Bank, 1986.

[6] M. Sayers, Two quarter-car model for defining road roughness: IRI and HRI. Washington, DC: Transportation Research Board, pp. 165-172, 1989.

[7] R. G. Dorsch, G. H. Usler, and J. M. Herrmann, "Laser triangulation: fundamental uncertainly in distance measurement," Applied Optics, 1994, 33(7): 1306-1314.

[8] Z. Ji and M. C. Leu, "Design of optical triangulation deveices," Optics and Laser Technology, 1989, 21(5): 335-338.

[9] K. Goh, N. Phillips, and R. Bell, “The applicability of a laser triangulation probe to non-contacting inspection," International Journal of Production Research, 1986, 24(6): 1331-1348.

[10] T. Clarke, "The use of optical triangulation for high speed acquisition of cross section or profiles of structures," Photogrammetric Record, 1990, 13(7): $523-532$. 